\title{
Computational simulation of static/cyclic cell stimulations to investigate mechanical modulation of an individual mesenchymal stem cell using confocal microscopy
}

\author{
Zakieh Alihemmati $^{1}$, Bahman Vahidi*1, Nooshin Haghighipour ${ }^{2}$ and Mohammad Salehi ${ }^{3}$ \\ ${ }^{1}$ Division of Biomedical Engineering, Department of Life Science Engineering, Faculty of New Sciences and \\ Technologies, University of Tehran, Tehran, Iran. \\ ${ }^{2}$ National cell bank of Iran, Pasteur Institute of Iran, Tehran, Iran. \\ ${ }^{3}$ Department of Mechanical Engineering, University of Tehran, Tehran, Iran. \\ *Corresponding Author E-mail Address: bahman.vahidi@ut.ac.ir
}

\begin{abstract}
It has been found that cells react to mechanical stimuli, while the type and magnitude of these cells are different in various physiological and pathological conditions. These stimuli may affect cell behaviors via mechanotransduction mechanisms. The aim of this study is to evaluate mechanical responses of a mesenchymal stem cell (MSC) to a pressure loading using finite elements method (FEM) to clarify procedures of MSC mechanotransduction. The model is constructed based on an experimental set up in which statics and cyclic compressive loads are implemented on a model constructed from a confocal microscopy 3D image of a stem cell. Both of the applied compressive loads are considered in the physiological loading regimes. Moreover, a viscohyperelastic material model was assumed for the cell through which the finite elements simulation anticipates cell behavior based on strain and stress distributions in its components. As a result, high strain and stress values were captured from the viscohyperelastic model because of fluidic behavior of cytosol when compared with the obtained results through the hyperelastic models. It can be concluded that the generated strain produced by cyclic pressure is almost $8 \%$ higher than that caused by the static load and the von Mises stress distribution is significantly increased to about $150 \mathrm{kPa}$ through the cyclic loading. In total, the results does not only trace the efficacy of an individual 3D model of MSC using biomechanical experiments of cell modulation, but these results provide knowledge in interpretations from cell geometry. The current study was performed to determine a realistic aspect of cell behavior.
\end{abstract}

Key words: Cell specific model, finite elements method, mechanical modulation, stem cell.

\section{Introduction}

One of the main objectives of cell mechanics studies is investigating a fundamental cellular process from the macroscopic to microscopic scale. Cells respond to the applied forces in various temporal and spatial scales, such as proliferation, differentiation, alterations in their shape and regulation of gene expression [1,2]. Cell levels modeling was developed to study maturing adipocytes using acquired geometrical properties and analyzing increased effective stresses with cell maturation [3]. Attempts are on-going to detect the effects of mechanical loads on cell deformations using mechanotransduction, such as plasma membrane strain $[4,5]$. Also, a 3D computational soft matter model which can show that the cell can sense substrate elasticity was developed [6]. Previous investigations reported that in vitro loadings initiated mechanotransduction in different types of stimuli and in a controlled cell culture medium [7]. 
Since the nucleus plays an important role in the mechanical behavior of the cell, it has been modeled as an incompressible elastic material and the results revealed interactions between the deformed nucleus and cell adhesion [8].

Knowledge of cellular changes in response to alterations in cellular components is largely based on empirical studies which investigate how these changes would damage cells and tissues. Hence, researchers have used finite elements method (FEM) to study this issue and developed two and three-dimensional models using such approaches [9]. Simulations such as that conducted by Gefen (2010) have modeled mouse fibroblast cells in three dimensions and evaluated mechanical properties of the cells [10]. In another study, skeletal muscle cells were analyzed in an undifferentiated state with a 3D geometry and large cellular deformations in response to compressive and tensile loads were examined [11]. Elucidation of biomechanical factors is essential, because they affect cellular responses. Mechanotransduction mechanism can provide a novel guideline for mechanical modulation of cells based on cell-specific studies (for example regeneration, bone homeostasis, and cell therapies for osteoarthritis) $[12,13]$.

Stem cells can be used in cell and gene therapy for various types of diseases, because of their self-renewal and multi-lineage differentiation capabilities, and therefore, are considered as a suitable cell source for preparing an alternative tissue in regenerative medicine [14]. By developing a perspective in mechanical and architectural features, recent studies on cellular mechanical properties show that bone cells, cartilage cells, and fat cells exhibit different properties as compared to primitive mesenchymal stem cells (MSCs). While most stiff cells have the potential to differentiate into bone cells. Cells with higher viscosity have the potential to differentiate into chondrocytes and softer cells tend to differentiate into fat cells [15]. Another research by Guilak et al. [16] describes the mechanical regulation of a cell component (nucleus) and its behavior based on mechanotransduction mechanisms. In this regard, behavior of stem cells under platen compression were investigated using computational methods. The results showed that the cell can sense its substrate stiffness which is strongly related to the cell behaviors such as cell adhesion and migration [17].

Morphology of cells in general and MSCs in particular, make it possible to examine the effect of cell geometry on its fate and in particular differentiation [18,19]. Our previous study demonstrated stem cell responses to fluid shear stress based on a fluid structure interaction (FSI) simulation analyzing cell deformations. Tolerable levels of shear stress were exerted on a MSC which show intracellular stress and strain values as a response to oscillatory flow [20].

Standing on legs is a simple example of applied compressive loading on bone cells and cartilage. This investigation seeks to evaluate the mechanical behavior of the cell as a result of external or internal compressive loads. This analysis is so important to quantify the phenomena of regulating MSCs functions through mechanotransduction and in pressure ulcers and tissue injury researches such as investigations about cell compressive stimulations conducted by gefen [10]. Also, by virtue of new tools to aid stem cell therapy, stem cell was considered as an attractive choice to model cellular response based on 3D confocal imaging. In this research, the simulation is based on applying forces in the range which they occur within the body. Then, mechanophysiological conditions, such as what happens in articular cartilage, required for chondroinduction of MSCs are simulated through a compressive loading regime. The main objective is to analyze the deformed cell so as to determine the stress distribution within the cell and its internal components. A major novelty of this investigation is the incorporation of viscohyperelastic behavior for the realistic stem cell geometry. Furthermore, comparison between static and cyclic loads seems to be essential to design in vitro tests. A practical approach for such a study is to employ FEM analysis for generated stresses within the cell and its components due to the application of a compressive load over time. Thereafter, cell components stress distribution and deformation gradients and other desired parameters in large deformations were analyzed.

\section{Materials and methods}




\subsection{Cell culture and specifying $3 D$ dimensions of the cell for confocal microscopy imaging}

Mesenchymal stem cells were provided by the National Cell Bank of Pasteur Institute of Iran and were used as undifferentiated cells which kept in vitro in Dulbecco's Modified Eagle's medium (DMEM; with 4.5 g/L glucose Sigma-Aldrich, St. Louis, MO, USA), supplemented with 10\% fetal bovine serum (FBS) (Sigma-Aldrich) and $1 \%$ Penicillin/Streptomycin $(10000 \mathrm{u} / \mathrm{ml}$ penicillin and $10 \mathrm{mg} / \mathrm{ml}$ streptomycin). The cells in the second passage were trypsinized and prepared for the subsequent stages of the procedure. The smallest adjustable focal volume is of great importance when using confocal microscopy (Zeiss Bio-Rad MRC 1024 model). Here, fluorescent staining of cells (actin filaments) was used to identify the cell morphology and cells were fixed for permeability staining. One day before staining, 12000 cells were plucked off and partially trypsinized and grown upon the coverslip which is coated with collagen type I on a round cover glass. After $24 \mathrm{~h}$ of transfection, the cells are ready for staining. For the staining, initially, the cell culture medium was evacuated and the cells were washed several times with PBS. Then, they were covered with formaldehyde $3.7 \%$ in PBS for 3 to 5 min and after that the cells were fixed. After discharging the culture medium on the cells, they are washed several times with PBS. In the duration of $10 \mathrm{~min}$, the cells were treated in Triton X-100 $0.1 \%$ in PBS. This substance causes permeability of cell membranes until the color enters into the cells easily. The cells were washed several times with PBS and then dissolved Phalloidin was placed in PBS and the cells were incubated for 45 min. Over time, these cells were washed several times with PBS. Then, they get ready for imaging by confocal microscopy. In confocal microscopy, a laser light was irradiated along the $\mathrm{Z}$ axis to scan the cell surface area and the resulting data were converted to an image. Then, three-dimensional images were made using microscopic sections of different cell depths (Figure 1A). Maximum height and width of the cell, cell area, cell membrane area, and cell volume including nucleus were obtained by image $\mathrm{j}$. These data are shown in Table 1. After determining cell size, the obtained image was imported to CAD software and using the specified dimensions, the image was reconstructed as a 3D model (as shown in Figure 1).
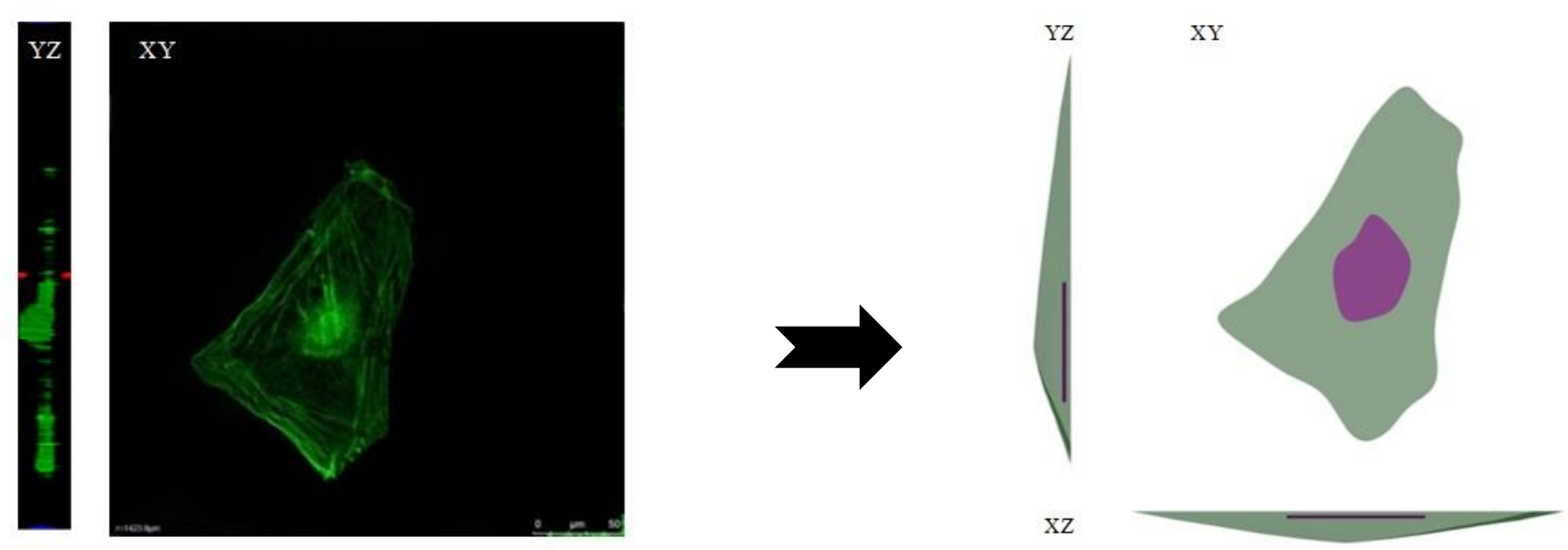

$\mathrm{XZ}$

Figure 1: Preparation and staining the cells with FITC Phalloidin; (A) principle and simplified optics of a confocal microscope; (B) three-dimensional image obtained by confocal microscopy. Scale bar: $50 \mu \mathrm{m}$. 


\begin{tabular}{|c|c|}
\hline Cell height $(\mu \mathrm{m})$ & 16 \\
\hline Maximum width of the cell $(\mu \mathrm{m})$ & 65 \\
\hline Cell area $\left(\mu \mathrm{m}^{2}\right)$ & $1767 / 16$ \\
\hline Area of the cell membrane $\left(\mu \mathrm{m}^{2}\right)$ & 0.2997 \\
\hline Cell volume $\left(\mu \mathrm{m}^{3}\right)$ & 6.9385 \\
\hline Surface area of the cell nucleus $\left(\mu \mathrm{m}^{2}\right)$ & 24486 \\
\hline Volume of the cell nucleus $\left(\mu \mathrm{m}^{3}\right)$ & 2.31283 \\
\hline
\end{tabular}

\subsection{Measurement of MSCs mechanical properties using Atomic Force Microscopy (AFM)}

Force-displacement data were obtained using AFM (Ara-Research Company, Tehran, Iran). Cells at passage 2 were transferred to a Petri dish, fixed for all motions with $4 \%$ Glutaraldehyde for $1 \mathrm{~min}$, and washed three times with PBS. The experimental procedure was performed using a dc probe with a conical tip which was fixed on the cantilever (with the spring constant at $0.15 \mathrm{~N} / \mathrm{m}$ and radius of $10 \mathrm{~nm}$ ).

AFM offers a topography image with 500 dots per cell with force (F) versus $\delta$ plots (the displacement of the cantilever). For an accurate calculation, reliability of the reported numbers, three cells, were selected randomly. For the first cell, the average indentation of 200 and $300 \mathrm{~nm}$ were used as an "effective stiffness" (ES) calculations, but in the second and the third cells, average indentation of 300 and $400 \mathrm{~nm}$ were used. For each indentation, the test is repeated four times. The following equation shows how to calculate $\delta$ [21]:

$$
\delta=\mathrm{Z}-\mathrm{F} / \mathrm{k}
$$

where $\mathrm{k}$ is the spring constant of the cantilever and its value is $0.15 \mathrm{nN} / \mathrm{nm}, \mathrm{F}$ and $\mathrm{Z}$ show, respectively $\delta$ and $\mathrm{F}$ of the AFM data. To calculate the ES, Hertz model shows the relationship of cone probe with cone radius of 10 nm below [20]:

$$
\mathrm{F}=\left(\mathrm{ES} /\left(1-\vartheta^{\wedge} 2\right)(2 \tan \alpha) / \pi\right) \delta^{\wedge} 2
$$

where $\alpha$ is the half angle of the cone and $\alpha=40^{\circ}$.

To study the behavior of adipose-derived MSCs, the cell was considered as a hyperelastic material. Furthermore, due to the lack of experimental data for many cell organelles, the cell membrane, cytoskeleton, and cytoplasm were considered as a single unit. Hence, the model consisted of two components: the cytoplasm and the nucleus which are the main responsive cellular organelles under compressive loading. To simulate the hyperelastic behavior of the cell, several hyperelastic models, including Mooney-Rivlin, Ogden, Hyper-foam, and SussmanBathe were considered, but only Sussman-Bathe curve was fitted to the AFM data (Figure 2). In each group, cytoplasmic network and the nucleus were assumed to be hyperelastic and linear elastic materials, respectively. 


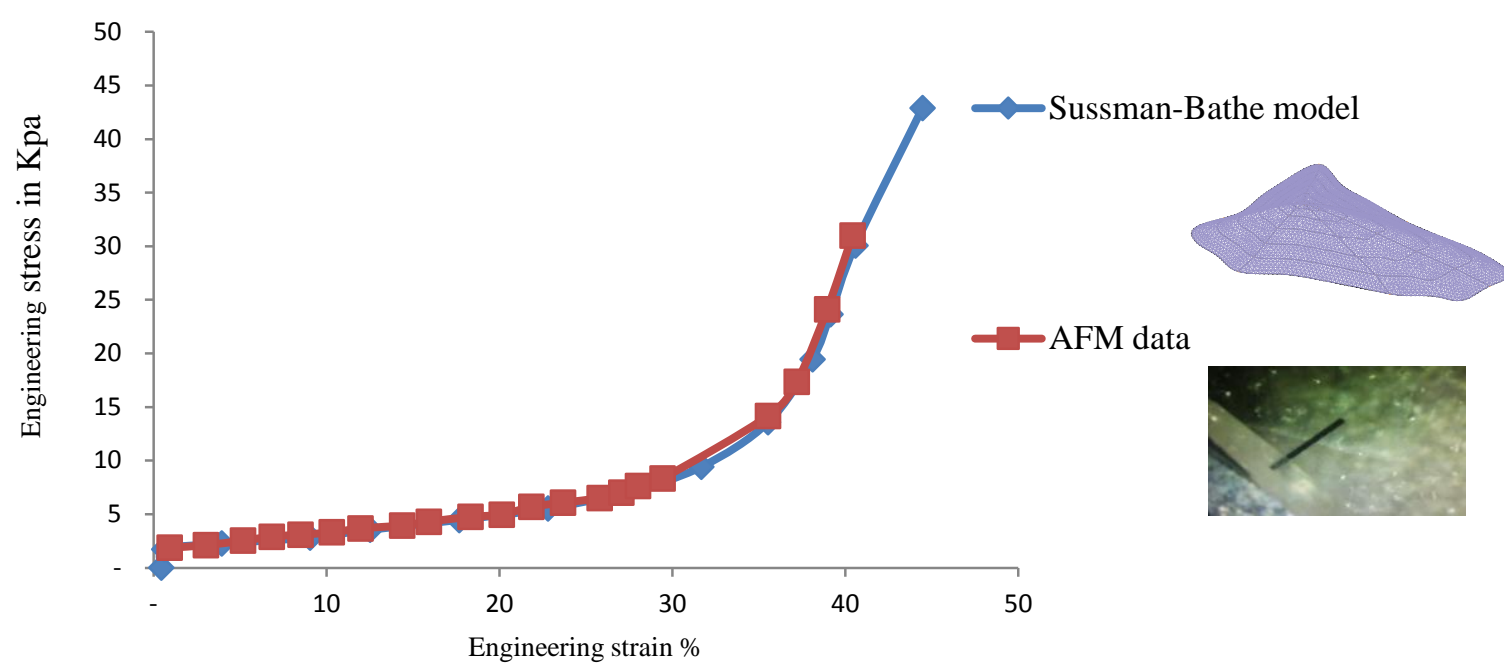

Figure 2: Stress-strain curve (The blue curve represents hyperelastic behavior fitted by Sussman-Bathe model and red bars are the stress-strain curve obtained from atomic force microscopy data.)

\subsection{Development of stem cell model and its components}

Figure 3 represents a loading test on the cell, like what happens in the joints as a result of being overweight and/or due to the application of a compressive load at the interface of tissue-bone [22, 23].

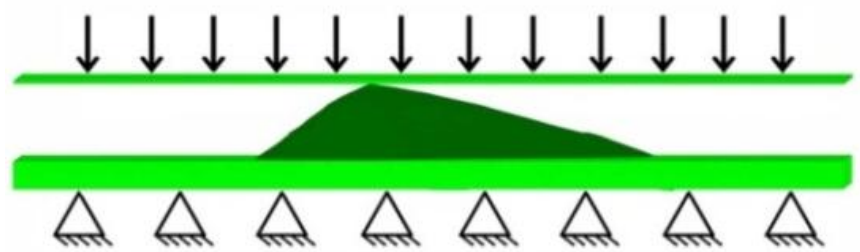

Figure 3: A schematic of loading on the cell.

Furthermore, to evaluate the resulting deformations of cells through deformations of cellular components under load application, the resulting stresses and strains were individually checked over time (Table 2). Then, the resulting deformation gradients were analyzed as global cell deformation (GCD \%) ${ }^{1}$ [10] for cytoplasmic domain and nucleus.

Table 2: Detailed properties of the cell models in each group.

\begin{tabular}{|c|c|c|c|c|c|}
\hline Cellular components & $\begin{array}{c}\text { Thickness / radius } \\
(\mu \mathrm{m})\end{array}$ & $\begin{array}{c}\text { Young's modulus } \\
(\mathrm{Mpa})\end{array}$ & Poisson's ratio & Density $(\mathrm{gr} / \mathrm{cm} 3)$ & Number of Elements \\
\hline nucleus & 5 & $0.001[24]$ & $0.4[10]$ & $1.4[26]$ & 548 \\
\hline cytosol & 10 & $0.0029[25]$ & $0.4[10]$ & $1.26[26]$ & 3183 \\
\hline Cell membrane & 0.5 & $0.0065[26]$ & $0.4[10]$ & $1.12[27]$ & 2239 \\
\hline
\end{tabular}

An important point in this study was related to the geometries of cellular components used in the model. Such cellular components (cytoplasm and nucleus) were separately reconstructed. Natural location of nucleus is in the center of gravity within the cell. In the produced three-dimensional image obtained from confocal microscopy, the approximate location of nucleus was specified [28]:

$$
\mathrm{V}_{\mathrm{Nuc}}=1 / 3 \quad \mathrm{~V}_{\text {Cell }}
$$

\footnotetext{
${ }^{1} \mathrm{GCD}[\%]=($ Height of undeformed cell-Height of deformed cell $) /($ Height of undeformed cell)
} 
In order to study large deformations caused by compressive loading and develop models of human MSCs, two models were used to investigate cell behavior (Table 3).

Table 3: Specifications of the developed models.

\begin{tabular}{|c|c|}
\cline { 2 - 2 } \multicolumn{1}{c|}{} & Cell properties \\
\hline $1^{\text {st }}$ group & $\begin{array}{c}\text { Cell and its components without effects of viscoelasticity in static } \\
\text { loading }\end{array}$ \\
\hline $2^{\text {nd }}$ group & $\begin{array}{c}\text { Cell and its components considering viscoelastic effects (viscohyper } \\
\text { elastic properties) in static loading }\end{array}$ \\
\hline $3^{\text {rd }}$ group & $\begin{array}{c}\text { Cell and its components without effects of viscoelasticity in cyclic } \\
\text { loading }\end{array}$ \\
\hline
\end{tabular}

The cell was assumed as a hyperelastic, isotropic, and incompressible solid. In this paper, Sussman-Bathe model was used according to the energy density function formula used by them. The relationship between stress and strain energy density function is given by the first derivative [29]:

$$
w^{\prime}(e)=\sum_{k=0}^{\infty}\left[\sigma\left(\left(\frac{1}{4}\right)^{k} e\right)+\sigma\left(-\frac{1}{2}\left(\frac{1}{4}\right)^{k} e\right]\right.
$$

In Sussman-Bathe model, $\mathrm{w}^{\prime}$ is used for uniaxial deformation to explain the true strain term "e". This model uses strain energy density function, in which $\mathrm{W}$ is the strain energy function which is a sum of separable energy density function $\mathrm{w}$ and $\mathrm{e}$ is used as the true strain. The model is used to determine tension, $\sigma$, which can be expressed as a function of true strain. So, the first derivative of strain energy density function can be integrated to obtain the following function [29]:

$$
W=\sum_{i=1}^{3} w\left(e_{i}\right)
$$

Finally, uniform cubic splines are used to calculate strain energy function W. Sussman-Bathe model do not need to fit using material constants.

\subsection{Simulation process}

Four-node three-dimensional solid elements were used with open network discretization of the solid, for the cell models. ADINA package (ADINA R\&D Inc., Watertown, MA, USA) was used to solve the finite element equations. The number of (tetrahedron) elements in each group of the models is shown in Table 4.

Table 4: Number of elements in two groups of the models to assess independency of numerical solutions from mesh density size.

\begin{tabular}{|c|c|c|c|c|}
\hline \multirow{2}{*}{ Group } & \multicolumn{3}{|c|}{ Mesh density in the model } & \multirow{2}{*}{ Element type } \\
\cline { 2 - 5 } & Coarse mesh & Intermediate mesh & Fine mesh & LPBE* \\
\hline $1^{\text {st }}$ group & 22522 & 37630 & 71370 & LPBE \\
\hline $2^{\text {nd }}$ group & 22537 & 37633 & 71372 & LPBE \\
\hline $3^{\text {rd }}$ group & 22532 & 37640 & 71375 & \\
\hline
\end{tabular}

$*$ LBPE $=$ Four-node quadrilateral 3D solid type

It is worth mentioning that in this study, attempt was made to reach an efficient time step so as to decrease the computational costs as much as possible. The equations were solved using sparse solver, since this method has a higher speed than other methods and occupies less computer memory [30]. In this model, Face link connections are used to initiate communication between cell membrane meshes-cytosol meshes and cytosol meshes-nucleus meshes. To examine the sensitivity of solutions to mesh size, three mesh sizes (large, medium, and small) were used in the models and then parameters corresponding to the desired response (displacement, strain, and stress 
values at the node with the highest strain) were studied for each mesh size. For analyzing mesh sensitivity, size of the elements was changed until the difference between responses became smaller than 5\%. Figure 4 illustrates alterations in the measured parameters when solving the equations in the computational models. To achieve a balance between accuracy and efficiency, the medium mesh density was used for simulation so as to reduce the cost of calculations.
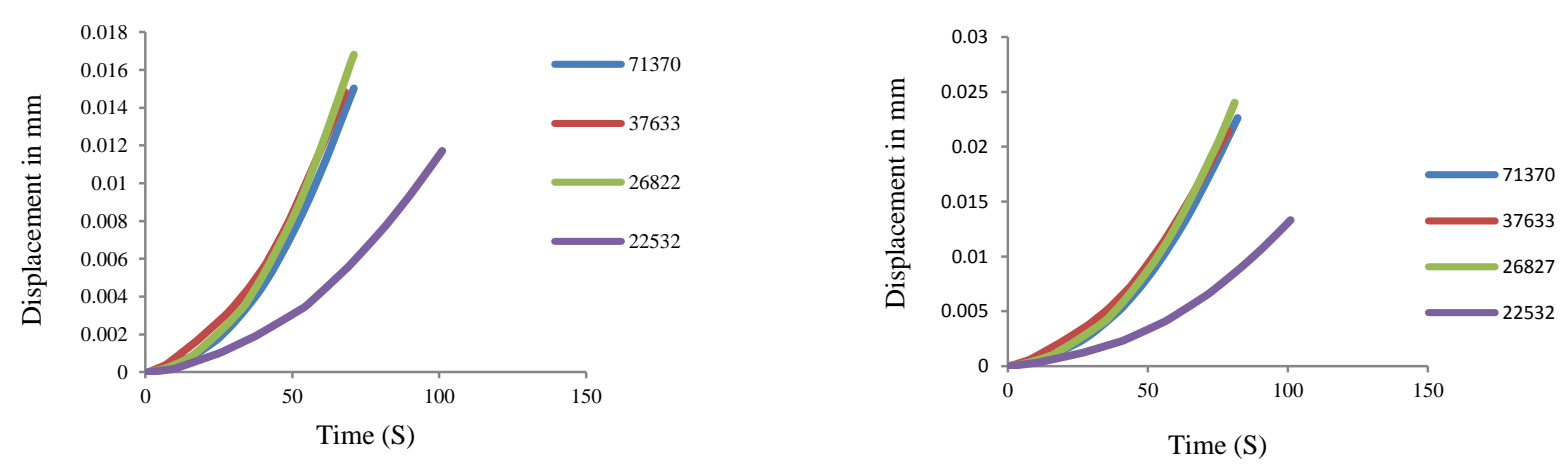

Figure 4: Independency of the results from numerical grid; (A) first group; (B) second and third groups.

\section{Results}

\subsection{Strain distribution}

\subsubsection{The first group}

Deformation gradients and strains were studied at nodes with maximum strain and generalized for the whole model. As shown in Figure 5A to C, the maximum level of deformation was generated in the interface between the cytoplasm and the inner parts under compression. Strain distribution in the direction of applied load (Y axis) is less than the other two directions. Strain gradient increases from $\mathrm{X}$-axis to Z-axis (the generated strain is tensile strain which is increased from the $\mathrm{X}$-axis with negative values towards $\mathrm{Z}$-axis with positive values).

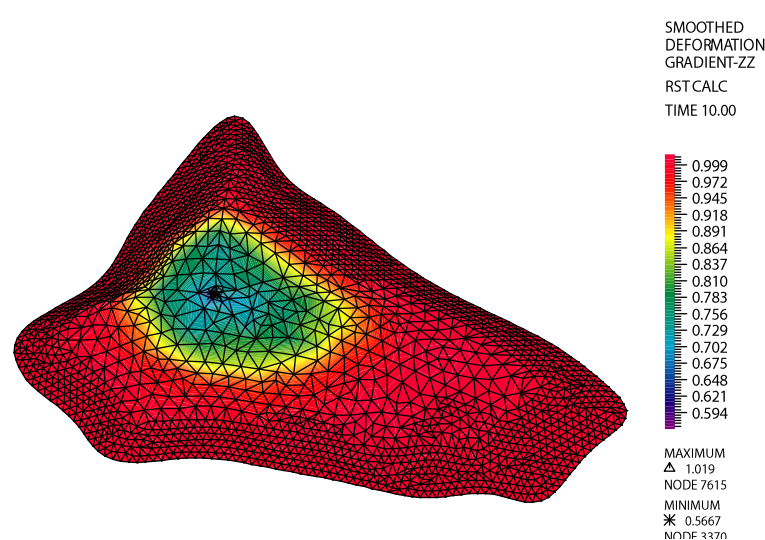

A

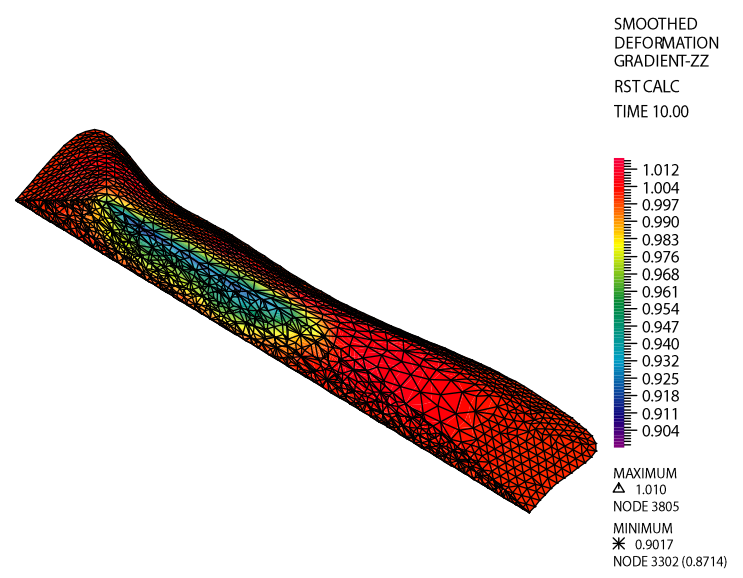

B 


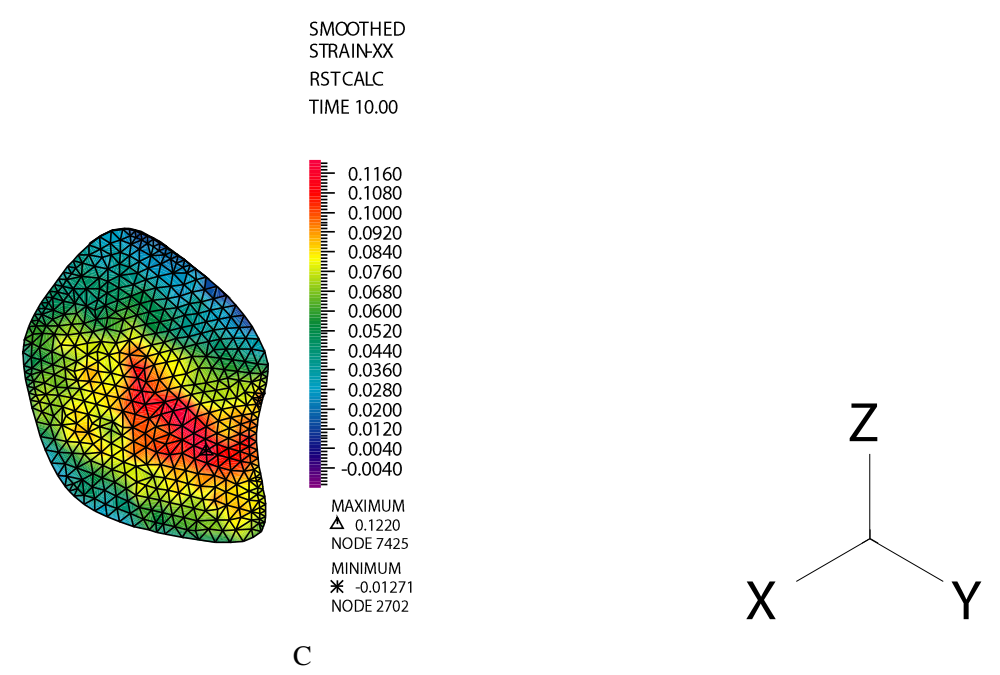

Figure 5: Deformation gradient distribution regardless of viscoelasticity by applying compressive load: (A) cytoplasm; (B) a section in Z-axis direction of the cell model; (C) nucleus.

According to Figure 6A and B, by applying a compressive force in the physiological range, the average levels of deformation in the cytoplasm and nucleus are 17.81 and 0.15 , respectively. These values show that cytoplasm undergoes large deformation (a deformation value more than $15 \%$ is considered as large deformation [10]).

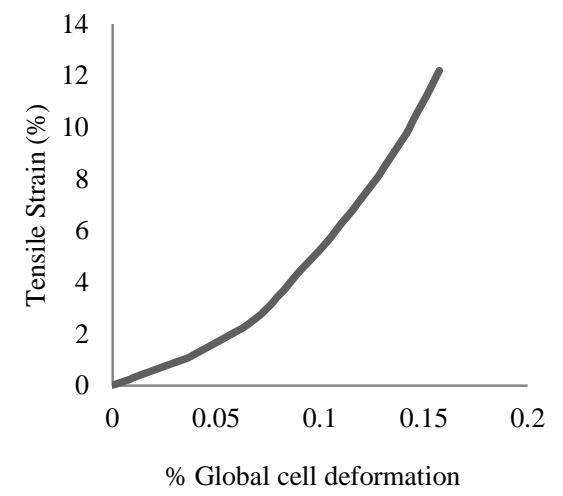

A

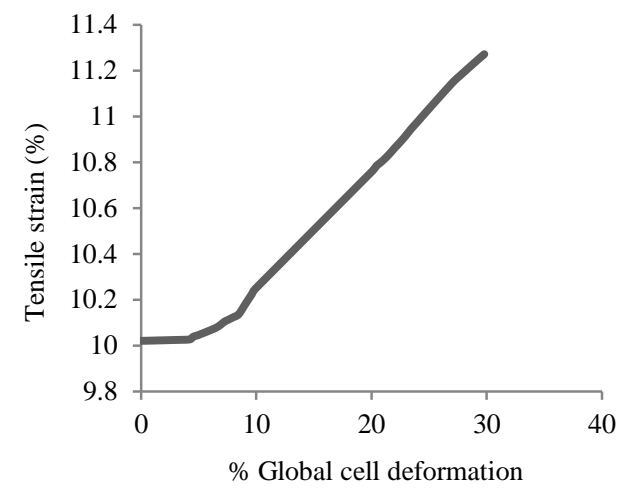

B

Figure 6: Compressive strain diagram: (A) by considering linear elastic properties for the cell nucleus; (B) cytoplasm exhibiting hyperelastic properties (Charts are drawn on the node with the highest strain).

\subsubsection{The second group}

The second model provides more accurate information about cell geometrical changes and compressive loading results. By applying a compressive load in the physiological range, the resulting deformations in the cytoplasmic domain are shown in Figure 7A-C. Comparison between Figure 5A (the first group) and Figure 7A (the second group) reveals almost $7 \%$ increase in the deformation rate in the cytoplasm. As observed for the second group, the maximum deformation occurs at the interface between the cytoplasm and the nucleus. As sections of the models show, deformations of the internal parts of cytoplasm are higher than its superficial regions. 


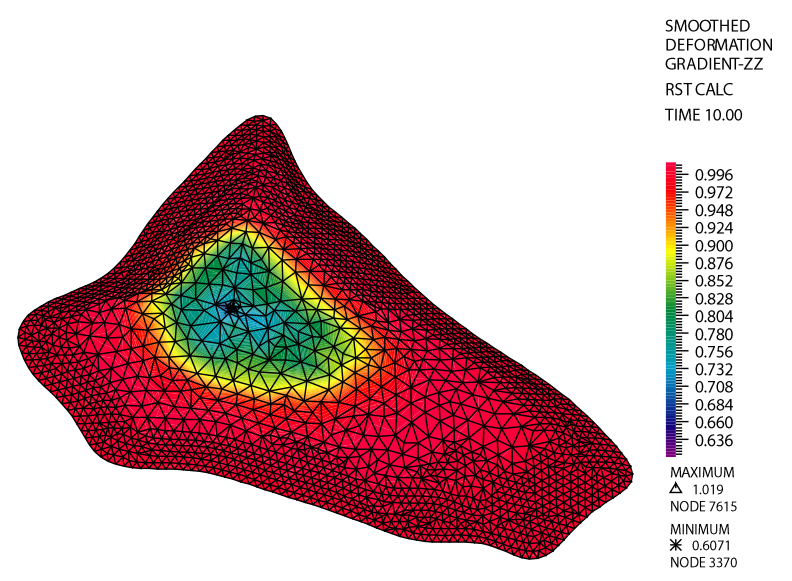

A

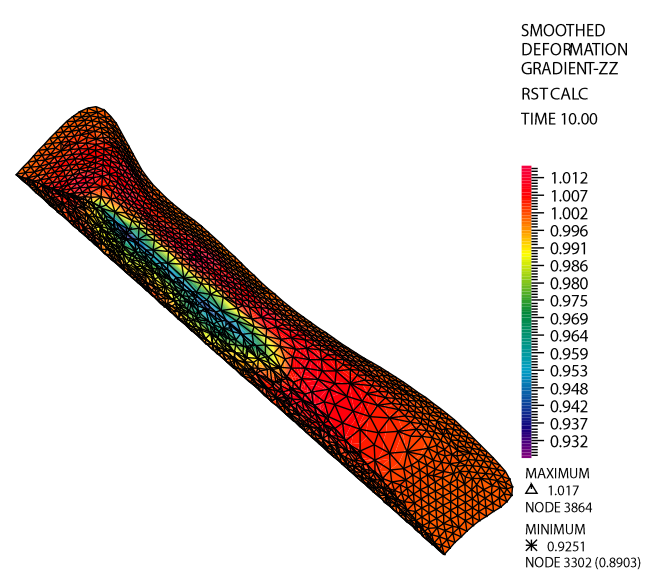

B

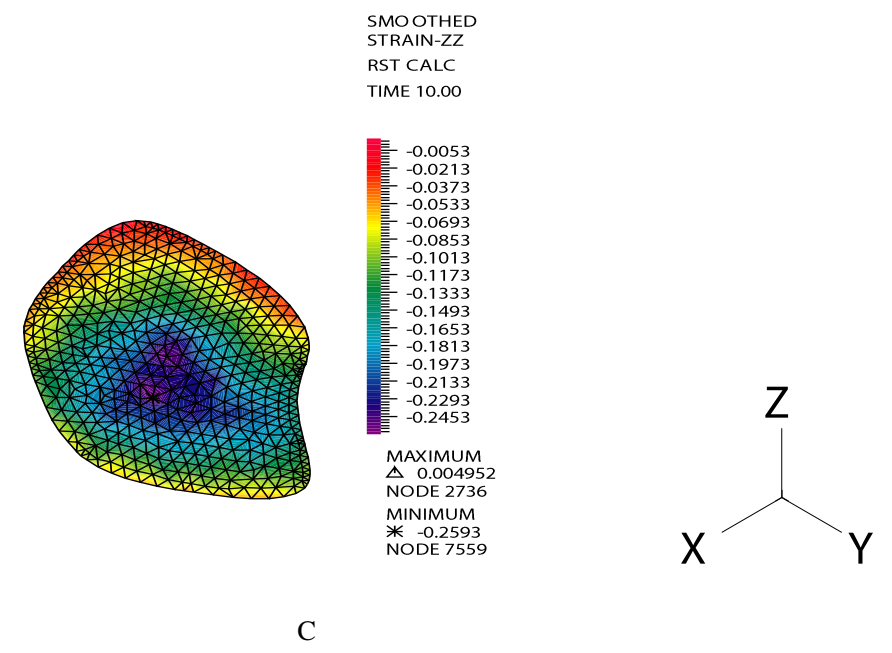

Figure 7: Deformation gradients distribution in hyperelastic and viscohyperelastic models by applying compressive load in the deformation gradients in hyperelastic model in: (A) cytoplasm; (B) a section in $\mathrm{Z}=$ axis direction of the cell model; (C) nucleus.

On the other hand, average deformation in the cytoplasm and nucleus was $30 \%$ and $0.3 \%$, respectively in the viscohyperelastic model. As expected, nucleus showed the lowest deformation due to its higher mechanical strength (the compressive strain diagram is provided in supplementary data Figure S1). These values show that cytoplasm undergoes large deformation [10].

\subsubsection{The third group}

In the other mode, instead of exerting a static load, a cyclic compressive load was applied to the cell so as to make the model closer to the in vivo conditions of MSCs chondroinduction. The applied frequency was $1 \mathrm{~Hz}$ [31]. Cyclic loads caused an increase in the tensile strain in cellular components (cytoplasm and nucleus). Generated strain values in the cytoplasm and nucleus were $18 \%$ and about $12 \%$, respectively. The generated strain in both groups showed that the strain produced by the cyclic pressure was almost $8 \%$ higher than that caused by the static load (Figure 8A to C). 


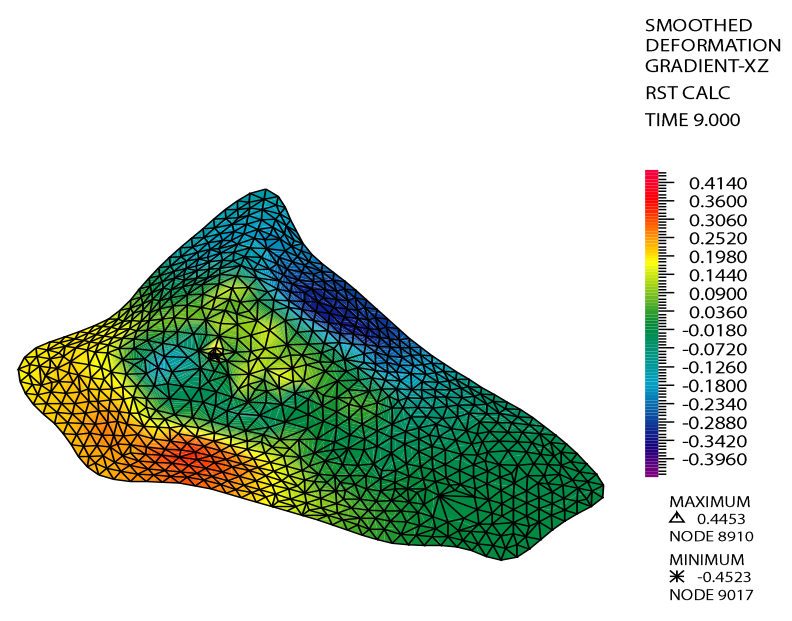

A

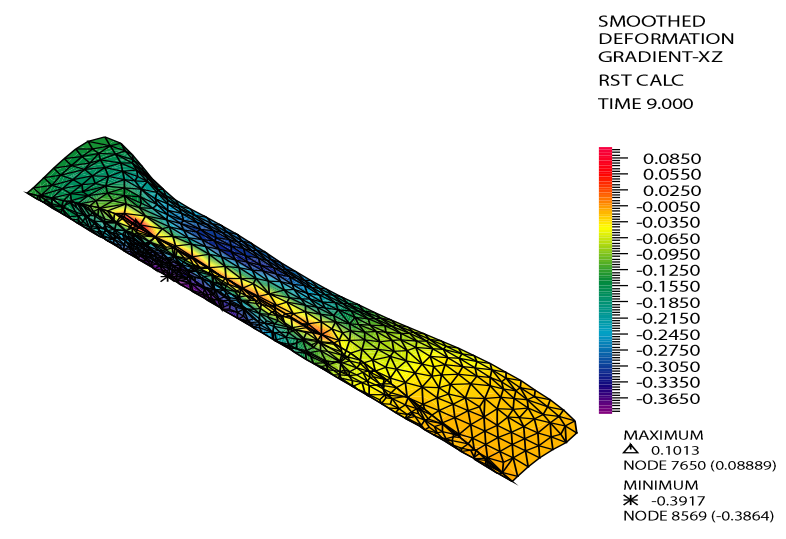

B

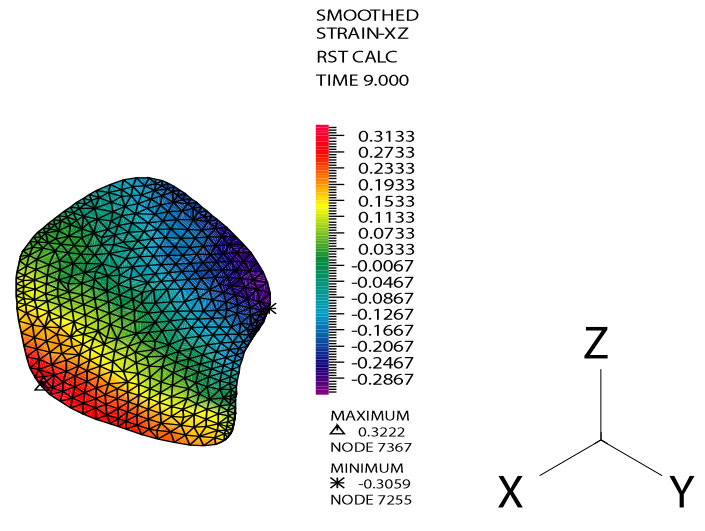

C

Figure 8: Deformation gradients distribution of cellular components due to application of a compressive cyclic load: (A) cytoplasm; (B) section of the cytoplasm model along the $\mathrm{X}$-axis; and (C) cell nucleus.

The strain values corresponding to the static and cyclic loadings are illustrated in Figure 9A and B.

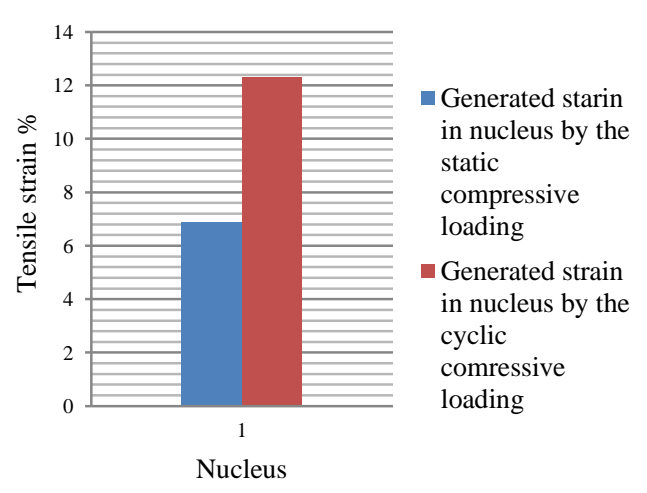

A

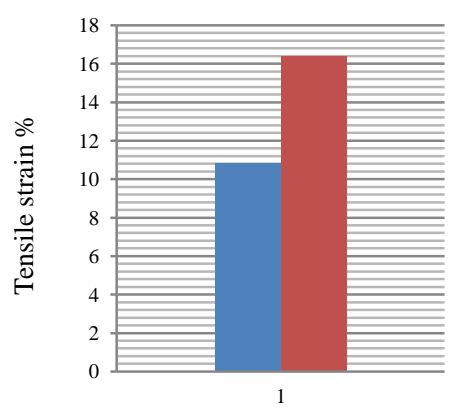
- Generated strain in cytoplasm by the static compressive loading
- Generated strain in cytoplasm by the cyclic compressive loading

Figure 9: Maximum internal strain recorded for the: (A) nucleus and (B) cytoplasm (8\% increase in the strains of cytoplasm and nucleus are observed as a result of cyclic loading).

\subsection{Stress distribution}




\subsubsection{The first group}

Stress analysis was performed at nodes with maximum strain and generalized for the whole model. Stresses produced in the cellular components by the static compressive loads in cytoplasm and nucleus and in the upper part of the cell were higher than those produced in other regions (Figure 10A to C).

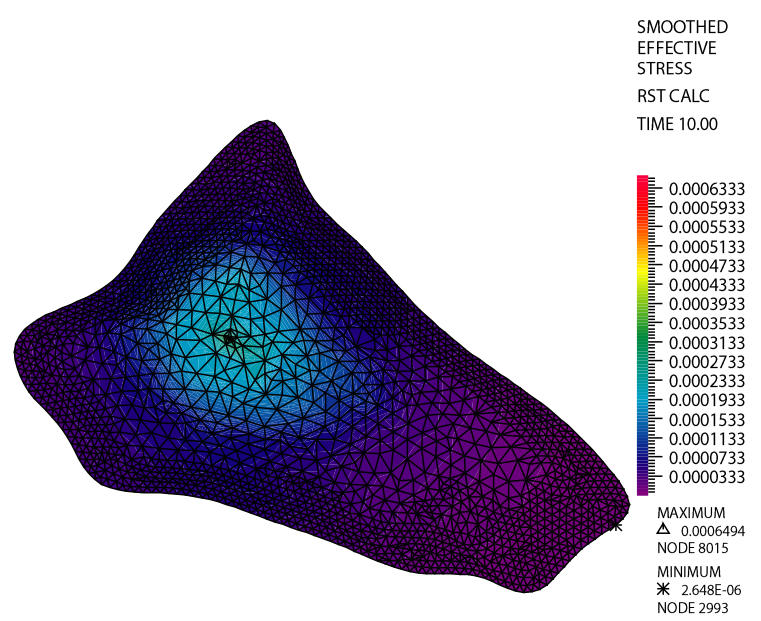

A

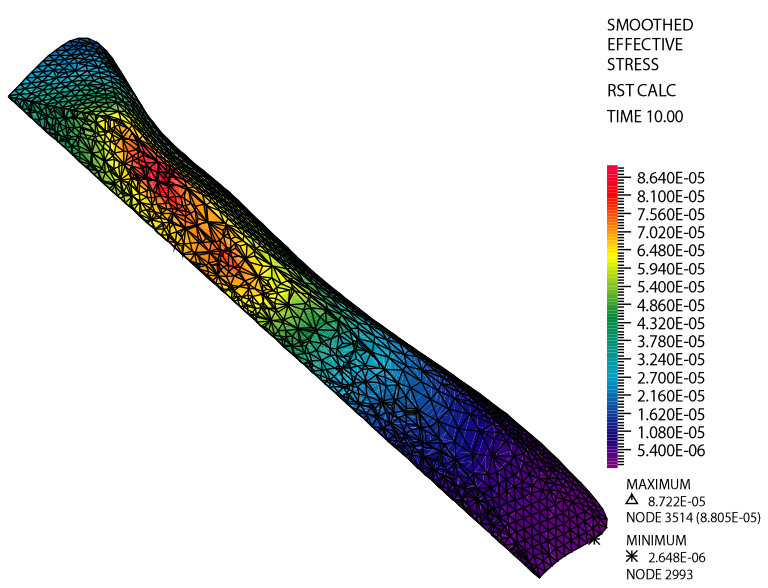

B

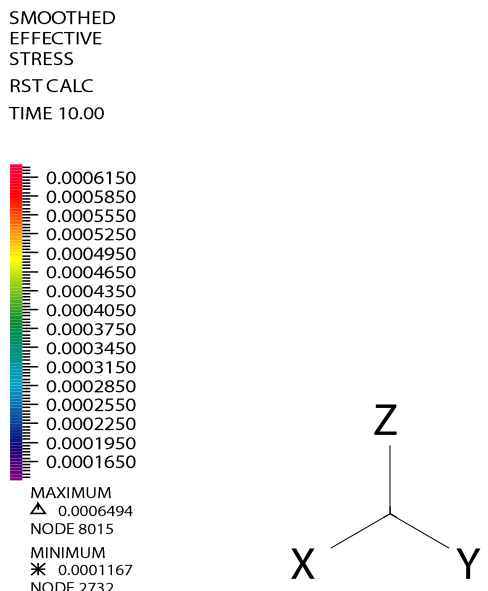

$\mathrm{C}$

Figure 10: (A) Distribution of von Mises stress in the hyperelastic model: (A) the cytoplasm; (B) section of the cytoplasm model; (C) the cell nucleus under a static compressive load.

The generated stresses in cytoplasm and nucleus were 8.6 and $0.61 \mathrm{kPa}$, respectively. These results can be explained by the higher stiffness of nucleus as compared to other network components (the compressive strain diagram is provided in supplementary data Figure S2).

\subsubsection{The second group}

Stresses which occurred in the cellular components in cytoplasm and nucleus (assuming the hyperelastic model) in the upper part of the cell were higher than those which occurred in other regions. Stress analysis in the cellular components in the viscohyperelastic model demonstrated that stress distribution at the surface, especially at the interface between the cytoplasm and nucleus was higher than that in the other parts (Figure 11A to C). The generated stresses in the cytoplasm and nucleus under hyperelastic behavior were 8.6 and $0.61 \mathrm{kPa}$, respectively. 


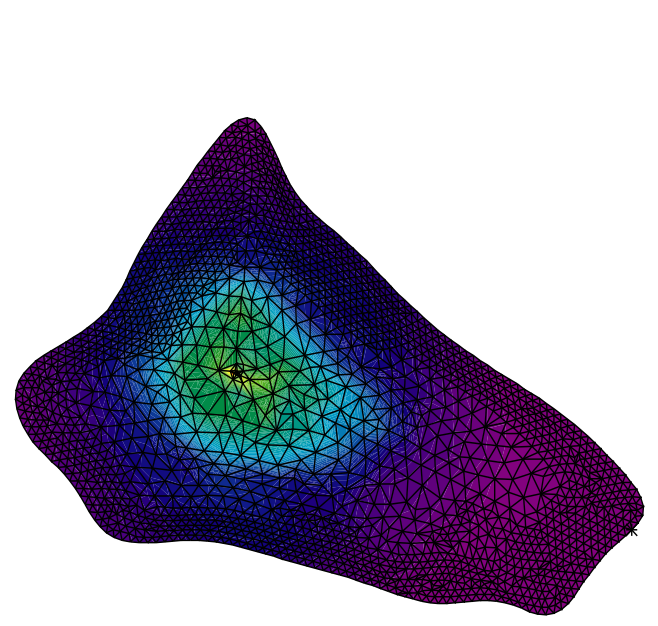

A

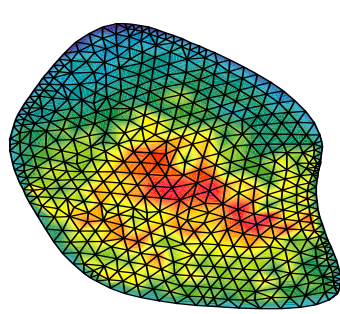

TIME 10.00

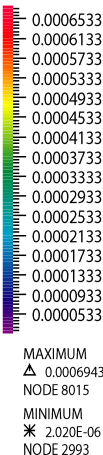

NODE 2993

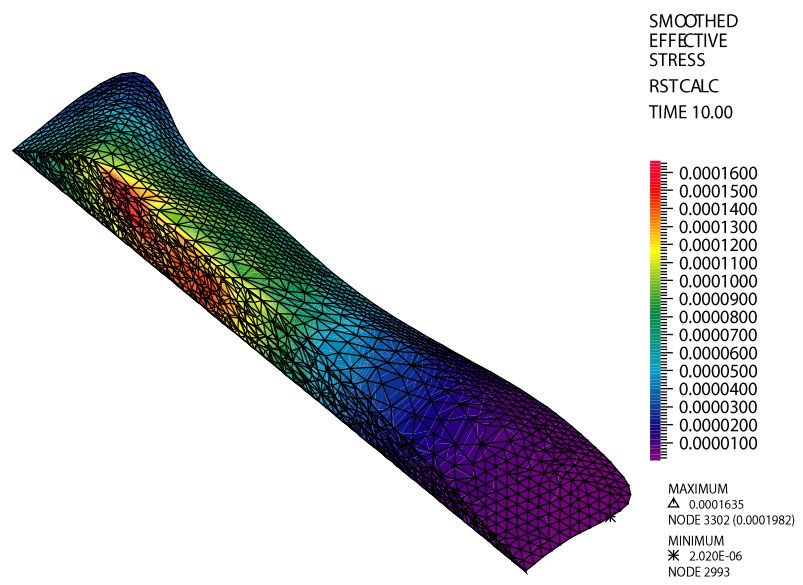

B

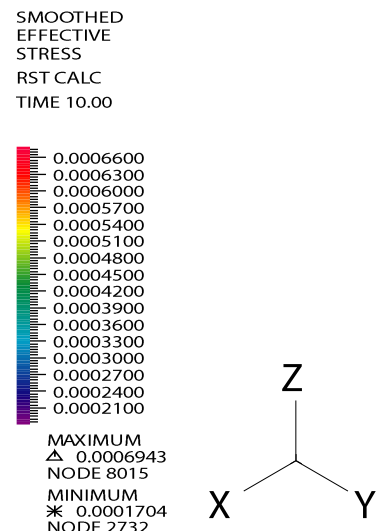

$\mathrm{C}$

Figure 11: Distribution of von Mises stress in the viscohyperelastic model: (A) cytoplasm; (B) a section of the cytoplasm; (C) cell nucleus under a static compressive load.

These results can be explained by the higher stiffness of the nucleus as compared to the other network components. The produced stresses in the cellular components were also investigated. Analysis of stress distributions in hyperelastic and viscohyperelastic assumptions shows that taking the fluid viscosity into account resulted in almost doubled values for the generated stresses in the cytoplasm (the compressive strain diagram is provided in supplementary data Figure S3).

\subsubsection{The third group}

As shown in Figure 12A to $\mathrm{C}$, von Mises stress distribution was significantly increased. The resulting tensile stress values in the cytoplasm and nucleus were 0.225 and $0.35 \mathrm{kPa}$, respectively. 


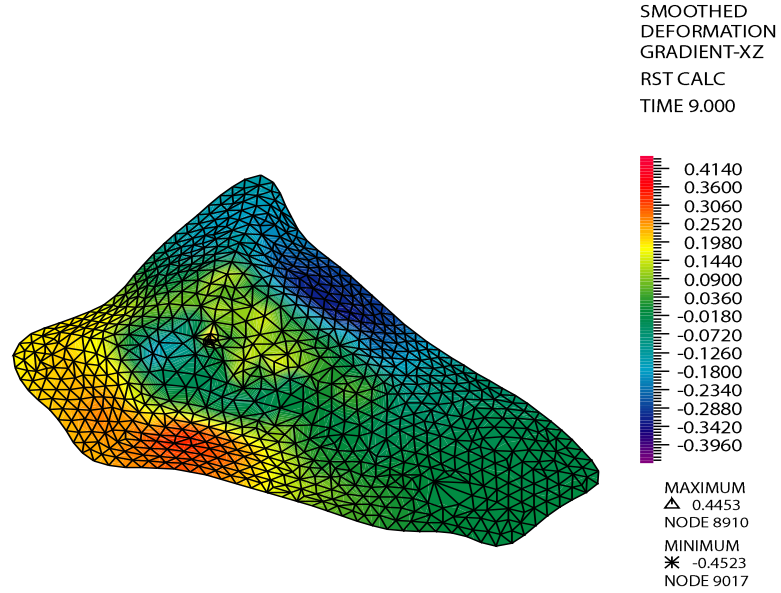

A

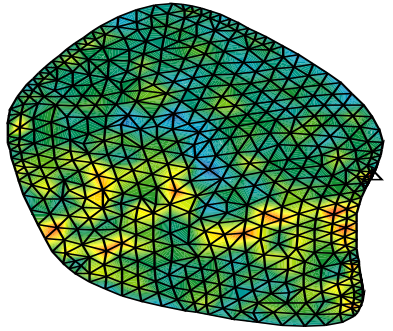

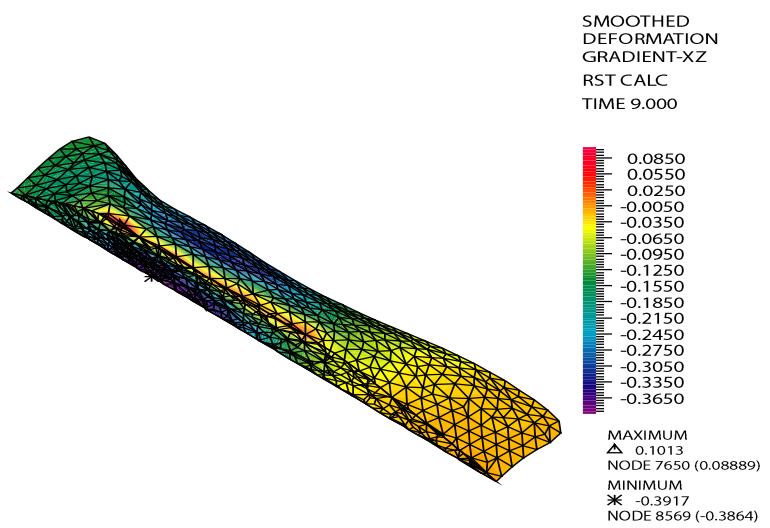

B

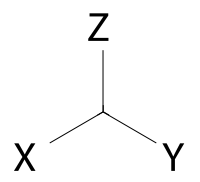

$\mathrm{C}$

Figure 12: Distribution of von Mises stress in cellular components as a result of cyclic pressure application: (A) cytoplasm; (B) section of the cytoplasm model along the $\mathrm{X}$-axis; and $(\mathrm{C})$ cell nucleus under a cyclic compressive load.

Due to the linear elastic behavior of the cell nucleus, stress values in the nucleus were higher than those in the cytoplasmic network. The stress values corresponding to static and cyclic loadings are illustrated in Figure 13. In both cases, stress was increased to about $150 \mathrm{kPa}$. 


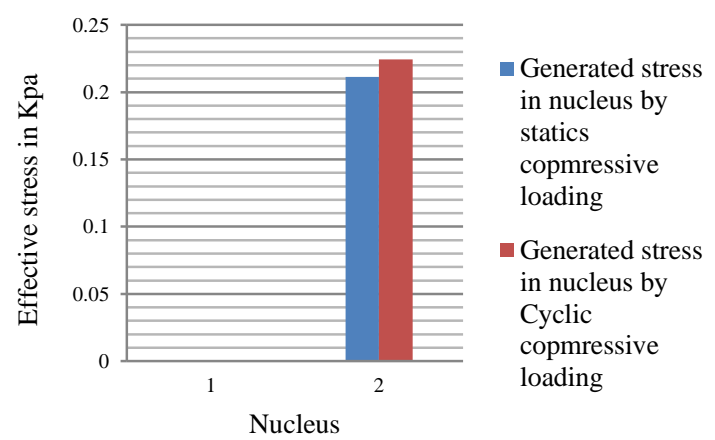

A

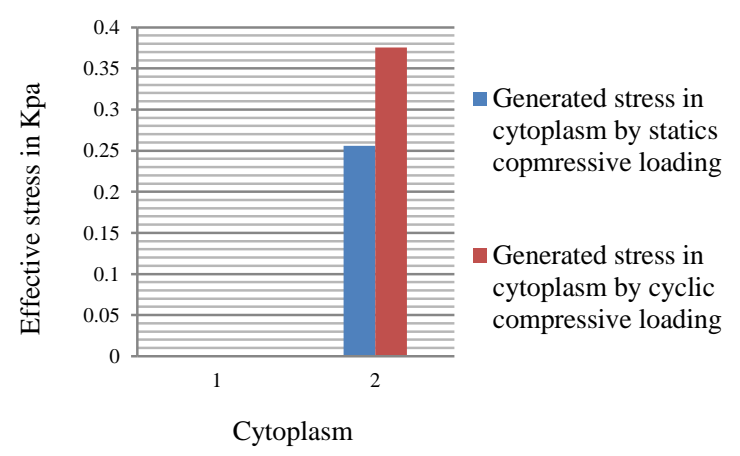

B

Figure 13: von Mises stress distribution in the cellular components due to the cyclic load in the: (A) nucleus and (B) cytoplasm (the difference between static and cyclic tensile stress values is about $0.15 \mathrm{kPa}$.)

\section{Discussion}

In this paper, a numerical simulation was proposed to analyze the mechanical response of an individual MSC to compressive statics and cyclic loading. The simulation is based on 3D images of MSCs obtained from the confocal microscopy and used as a source for designing a 3D model to determine the geometrical parameters of the cell model in physiological loading regimes [32]. Finite element analysis was performed using AFM data and an asymmetric model including an actual geometry of the cell to improve realistic assumptions of the FEM model. In the case of the amount of deformations, von Mises stresses and internal strains were dropped. Nevertheless, the generated strain was more than 5\% in the cytoplasm, which underwent large deformations (also, deformation value of more than $15 \%$ is considered as large deformation) $[10,11]$. The strain distributions in the model indicated the probable mechanical modulation of MSCs behavior as a result of conversion of mechanical stimuli into biochemical signals $[33,17]$.

Cytoplasm is as a composite material made of cytosol, cytoskeleton fibers, and other organelles. The cytosol fluidity affects other cellular components and on the mechanical behavior of the cell under compressive loading [34]. So, two groups of models were considered (Table 3). Magnitudes of the cyclic compressive loads were similar to the static conditions, but the strain and stress values significantly increased due to the cyclic load. Thus, magnitudes of applied forces on the cell can be reduced by applying a cyclic force and by this computational analysis, suitable strain gradients can be achieved for future stem cell strategies under laboratory conditions, such as differentiation, proliferation, and migration.

The results of this study showed that internal organization of adipose-derived MSCs which depends on cell mechanical properties was affected by cell stimulations. These findings further support the suggestion of previous research carried out on bone-derived cells. In the study, it was shown that the in vitro methods, especially in the implementation of mechanical stimuli, affected the generated strains in the internal components of the cell as a result of different kinds, modes and magnitudes of stimulations such as vibration, fluid shear, substrate deformation and compressive loading within a parallel-plate [35].

Chooi [36], in an in vitro strain information investigation, reported the effects of compressive loading on stress response in the induction and control of expression at different rate of strain (30 and 70\%) [36]. The magnitude of stress and strain have been determined in the previous research using human MSCs cultured in 3D collagen matrices and subjected to global cyclic tensile strains of 10 and 12\% [37]. Furthermore, a conducted research on cartilage and chondrocyte showed that the nonlinear behavior of this tissue resulted in creation of magnitudes of 
compressive strains less than $20 \%$ under physiological compressive stresses [38]. Also, the plasma membrane has deformation resistance based on the fact that the underlying cytoskeleton and actin fibers respond to loading and provide resistance to the external force due to their viscoelastic behavior [39, 40]. Based on the aforementioned findings, the use of AFM can be important to determine cell mechanical behavior [40]. Laboratory analysis of MSCs differentiation showed phenotype of linage such as neural $(0.1-1 \mathrm{kPa})$, myogenic $(8-17 \mathrm{kPa})$ or osteogenic (>34 kPa) [41]. MSCs, under compressive loading, have the potential to differentiate into cartilage cells [33]. The formation of such cells is possible by changing the amount of strain through the loading process (the required strain gradients for the stimulation/expression of bone and cartilage genes are 15\% and $10 \%$, respectively) [33]. The results of the present study (strain of $\sim 12 \%$ ) are in accordance with these physiological values, and to achieve the desired results, one can apply the load in the physiological range so as to generate a strain of about $12 \%$.

In this investigation, the viscohyperelastic behavior was chosen to describe the nonlinear mechanical properties of a stem cell by fitting the Sussman-Bathe model to the experimental -strain data. This approach made it possible to perform a more realistic simulation. In this study, a three-dimensional image makes it possible to investigate the strain distributions in cellular components. It can be helpful to design more precise experiments to analyze modulation of cells in response to mechanical loadings [42, 43]. In order to direct cell fate toward a desired target tissue (such as, cartilage, bone, etc.), a mechanical loading was applied on stem cells according to previous studies and physiological/laboratory loading regimes [44, 45]. The results of this study showed that stem cell mechanotransduction mechanisms can be achieved by applying lower force levels in a cyclic mode as compared to the static mode. The main objective for this simulation was to clarify the mechanism of material exchange by converting applied mechanical forces into biochemical signals in the cell.

Despite some progress in cell-specific simulation of stem cells achieved in the present study, there exist some limitations in such simulations. The major problem in analyzing the data associated with the cytoskeleton is taking 3D images and designing a model for filaments. Another limitation is lack of experimental data for determining the exact mechanical properties of the cell. The obtained data from the simulation shows that observed changes in the cytoplasm is probably due to the nonlinear behavior of the cytosol.

Considering some simplifications, deformation values can be analyzed using FEM. When considering loading, boundary conditions and the complex geometry are more time-consuming task. Consequently, simplifications should always be examined to ensure that they are not reducing the accuracy. This investigation was planned to provide a closer look at some of biological phenomena like mechanotransduction mechanisms of MSCs. Furthermore, the importance of types and magnitudes of laboratory parameters on MSCs biomechanical response can be seen more clear using a simulation tool especially in applying compressive loading.

Future studies on development of the current hyperelastic features are recommended to provide more realistic conditions for simulation of cell behavior. By combining hyperelastic behavior and the molecular mechanisms of MSCs, a model can be presented which is useful in both computational and clinical approaches, such as regenerative medicine and designing drug delivery systems.

\section{Conclusions}

Conclusively, the current study was performed to determine a realistic cell behavior. MSCs in the body act as hyperelastic and viscoelastic materials under compressive loading. This computational model was created to prepare the geometry of the FEM model. As an appropriate tool to anticipate cell behavior, it can help to design new systems for in vitro loading experiments. Therefore, three-dimensional images of tissues or cells can be useful to obtain the actual geometry. A 3D model has been used to determine the mechanical behavior of MSCs on a larger scale which may lead to a deeper understanding of biomechanical properties of these cells. As a 
result, it is a suitable method for tissue engineering and it can quantitatively elucidate cellular mechanobiological phenomena.

\section{Acknowledgements}

The authors are grateful to the Iran National Science Foundation for the financial support of this project.

\section{References}

[1] E. Gladilin, P. Gonzalez, R. Eils, Dissecting the contribution of actin and vimentin intermediate filaments to mechanical phenotype of suspended cells using high-throughput deformability measurements and computational modelling, J. Biomsech. 47 (2014) 2598-2605.

[2] O. P. Hamill, B. Martinac, Molecular basis of mechanotransduction in living cells, Physiol Rev. 81 (2001) 685-740.

[3] R. Katzengold, N. Shoham, D. Benayahu, A. Gefen, Simulating single cell experiments in mechanical testing of adipocytes, Biomech Model Mechanobiol. 14 (2015) 537-547.

[4] N. Slomka, A. Gefen, Relationship between strain levels and permeability of the plasma membrane in statically stretched myoblasts, Ann Biomed Eng. 40 (2012) 606-618.

[5] E. Leopold, A. Gefen, Changes in permeability of the plasma membrane of myoblasts to fluorescent dyes with different molecular masses under sustained uniaxial stretching, Med Eng Phys. 35 (2013) 601-607.

[6] X. Zeng, Sh. Li, A three dimensional soft matter cell model for mechanotransduction, Soft Matter. 8 (2012) 5765-5776.

[7] R. M. Delaine-Smith, B. Javaheri, J. H. Edwards, M. Vazquez, R. M. H. Rumney, Preclinical models for in vitro mechanical loading of bone-derived cells, BoneKEy Reports. 4 (2015) 2047-6396.

[8] C. Giverso, A. Grillo, L. Preziosi, Influence of nucleus deformability on cell entry into cylindrical structures, Biomech Model Mechanobiol. 13 (2014) 481-502.

[9] N. Slomka, C. W. J. Oomensb, A. Gefen, Evaluating the effective shear modulus of the cytoplasm in cultured myoblasts subjected to compression using an inverse finite element method, J. Mech Behav Biomed Mater. 4 (2011) 15591566.

[10] N. Slomka, A. Gefen, Confocal microscopy-based three-dimensional cell-specific modeling for large deformation analyses in cellular mechanics, J. Biomech. 43 (2010) 1806-1816.

[11] S. Or-Tzadikario, A. Gefen, Confocal-based cell-specific finite element modeling extended to study variable cell shapes and intracellular structures: the example of the adipocyte, J. Biomech. 44 (2011) 567-573.

[12] K. V. Iyer, S. Pulford, A. Mogilner, G. V. Shivashankar, Mechanical Activation of Cells Induces Chromatin Remodeling Preceding MKL Nuclear Transport, J. Biophysical. 103 (2012) 1416-1428.

[13] B.O. Diekman, F. Guilak, Stem cell-based therapies for osteoarthritis: challenges and opportunities, J. Curr Opin Rheumatol. 25 (2013) 119-126.

[14] J.Y. Park, S. K. Kim, D. H. Woo, J. E. Lee, J. H. Kim, S. H. Lee, Differentiation of Neural Progenitor Cells in a Microfluidic Chip-Generated Cytokine Gradient, Stem Cells. 27 (2009) 2646-2654.

[15] R.D. González-Cruz, V. C. Fonseca, E. M. Darling, Cellular mechanical prop differentiation potential mesenchymal stem cells, J. Proc Natl Acad Sci USA. 109 (2012) 1523- 1529.

[16] R.P. Martins, J. D. Finan, F. Guilak, D. A. Lee, Mechanical Regulation of Nuclear Structure and Function, Annu Rev Biomed Eng. 14 (2012) 431-455.

[17] X. Zeng Sh. Li, Modelling and simulation of substrate elasticity sensing in stem cells, Comput Methods Biomech Biomed Engin. 14 (2011) 447-458.

[18] A. J. Keung, K. E. Healy, S. Kumar, D. V. Schaffer, Biophysics and dynamics of natural and engineered stem cell microenvironments, Wiley Interdiscip Rev Syst Biol Med. 2 (2010) 49-64.

[19] F. Guilak, D. M. Cohen, B. T. Estes, J. M. Gimble, W. Liedtke, C.S. Chen, Control of Stem Cell Fate by Physical Interactions with the Extracellular Matrix, Cell Stem Cell. 5 (2009) 17-26.

[20] R. Vaez Ghaemi, B. Vahidi, M. H. Sabour, N. Haghighipour, Z. Alihemmati, Fluid-Structure Interactions Analysis of Shear-Induce Modulation of a Mesenchymal Stem Cell: An Image-Based Study, Artif Organs. 40 (2016) 278-287.

[21] G.T. Charras, M.A. Horton, Determination of Cellular Strains by Combined Atomic Force Microscopy and Finite Element Modeling, J. Biophys. 83 (2002) 858-879.

[22] C. J O. Conor, N. Case, F. Guilak, Mechanical regulation of chondrogenesis, Stem Cell Res Ther. 4 (2013) 61. [23] L. Zhang, J. Hu, K. A. Athanasiou, The role of tissue engineering in articular cartilage repair and regeneration, Crit Rev Biomed Eng. 37 (2009) 1-57.

[24] C. W Harland, M. J. Bradley, R. Parthasarathy, Phospholipid bilayers are viscoelastic, Proc Natl Acad Sci USA (PNAS). 107 (2010) 19146-19150.

[25] S. A. Berger, L. D. Jou, Flows in stenotic vessels, Annu Rev. Fluid Mech. 32 (2000) 347-382.

[26] H. Hatami-Marbini, M. R. Mofrad, Cytoskeletal mechanics and cellular mechanotransduction: a molecular perspective, Cellular and Biomolecular Mechanics and Mechanobiology, Springer Berlin Heidelberg, 2011, pp. 3-27. 
[27] F. Guilak, J. R. Tedrow, R. Burgkart, Viscoelastic Properties of the Cell Nucleus, Biochem Biophys Res Commun. 269 (2000) 781-786.

[28] E. Gladilin, A. Micoulet, B. Hosseini, K. Rohr, J. Spatz, R. Eils, 3D finite element analysis of uniaxial cell stretching: from image to insight, Phys Biol. 4 (2007) 104-113.

[29] T. Sussman, K. J. Bathe, A model of incompressible isotropic hyperelastic material behavior using spline interpolations of tension-compression test data, J. Commun. Numer. Meth. Engng. 25 (2009) 53-63.

[30] L. Y. Zheng, D. S. Farnam, D. Homentcovschi, B. G. Sammakia, A Porous Elastic Model for Bacterial Biofilms: Application to the Simulation of Deformation of Bacterial Biofilms Under Microfluidic Jet Impingement, J. Biomech Eng. 134 (2012) 051003.

[31] C. Y. Huang, K. L. Hagar, L. E. Frost, Y. Sun, H. S. Cheung, Effects of Cyclic Compressive Loading on Chondrogenesis of Rabbit Bone-Marrow Derived Mesenchymal Stem Cells, Stem Cells. 22 (2004) $313-323$.

[32] E. A. Peeters, C. W. Oomens, C. V. Bouten, D. L. Bader, F. P. Baaijens, Mechanical and failure properties of single attached cells under compression, J. Biomech. 38 (2005) 1685-1693.

[33] R. M. Delaine-Smith, G. C. Reilly, Mesenchymal stem cell responses to mechanical stimuli, J. Muscles Ligaments Tendons. 2 (2012) 169-180.

[34] X. Zeng, Sh. Li, Multiscale modeling and simulation of soft adhesion and contact of stem cells

, J. Mech Behav Biomed Mater. 4 (2011) 180-189.

[35] N. Slomka, S. Or-Tzadikario, D. Sassun, A. Gefen, Membrane-stretch- induced cell death in deep tissue injury: computer model studies, J. Cell Mol Biol. 2 (2011) 118-132.

[36] W. H. Chooi, B. P. Chan, Compression loading-induced stress responses in intervertebral disc cells encapsulated in 3D collagen constructs, Sci Rep. 6 (2016) 26449.

[37] T. Wayne Pfeiler, R. D. Sumanasinghe, E. G. Loboa, Finite Element Modeling of 3D Human Mesenchymal Stem CellSeeded Collagen Matrices Exposed to Tensile Strain, J. Biomech. 41 (2008) 2289-2296.

[38] S. Park, C. T. Hung, G. A. Ateshian, Mechanical response of bovine articular cartilage under dynamic unconfined compression loading at physiological stress levels, Osteoarthritis Cartilage. 12 (2004) 65-73.

[39] J. D. Humphrey, E. R. Dufresne, M. A. Schwartz, Mechanotransduction and extracellular matrix homeostasis, Nat Rev Mol Cell Biol. 15 (2014) 802-812.

[40] K. Haase, A. E. Pelling, Investigating cell mechanics with atomic force microscopy, J. R Soc Interface. 12 (2015) 20140970.

[41] J. Snyder, A. Rin Son, Q. Hamid, C. Wang, Y. Lui, W. Sun, Mesenchymal stem cell printing and process regulated cell properties, Biofabrication. 7 (2015) 044106.

[42] T. N. Abbariki, M. A. Shokrgozar, N. Haghighipour, N. Aghdami, R. Mahdian, A. Amanzadeh, M. Jazayeri, Comparing the effect of uniaxial cyclic mechanical stimulation and chemical factors on myogenin and myh2 expression in mouse embryonic and bone marrow derived mesenchymal stem cells, Mol Cell Biomech. 1(2014) 019-037.

[43] F. Safshekan, M. Tafazzoli Shadpour, M. A. Shokrgozar, N. Haghighipour, S. A. Alavi, Effects of short-term cyclic hydrostatic pressure on initiating and enhancing the expression of chondrogenic genes in human adipose-derived mesenchymal stem cells, J. Mech. Med. Biol. 14 (2014) 1450054.

[44] D. Gawlitta, W. Li, C. W. Oomens, F. P. Baaijens, D. L. Bader, C. V. Bouten, The relative contributions of compression and hypoxia to development of muscle tissue damage: An invitro study, Annu Rev Biomed Eng. 35 (2007) 273-284.

[45] E. A. G. Peeters, C. W. J. Oomens, C. V. C. Bouten, D. L. Bader, F. P. T. Baaijens, Viscoelastic properties of single attached cells under compression, J.Biomech Eng. 127 (2005) 237-243. 


\section{Graphical abstracts}

Based on confocal microscopy images and through finite elements analysis, we simulate mechanical behavior of the stem cell components (the cell membrane, cytoplasm and nucleus) under a compressive load. A major novelty of this investigation is the usage of viscohyperelastic behavior for the realistic stem cell geometry. High strain and stress values were captured from the viscohyperelastic model compared with the obtained results through the hyperelastic models. 


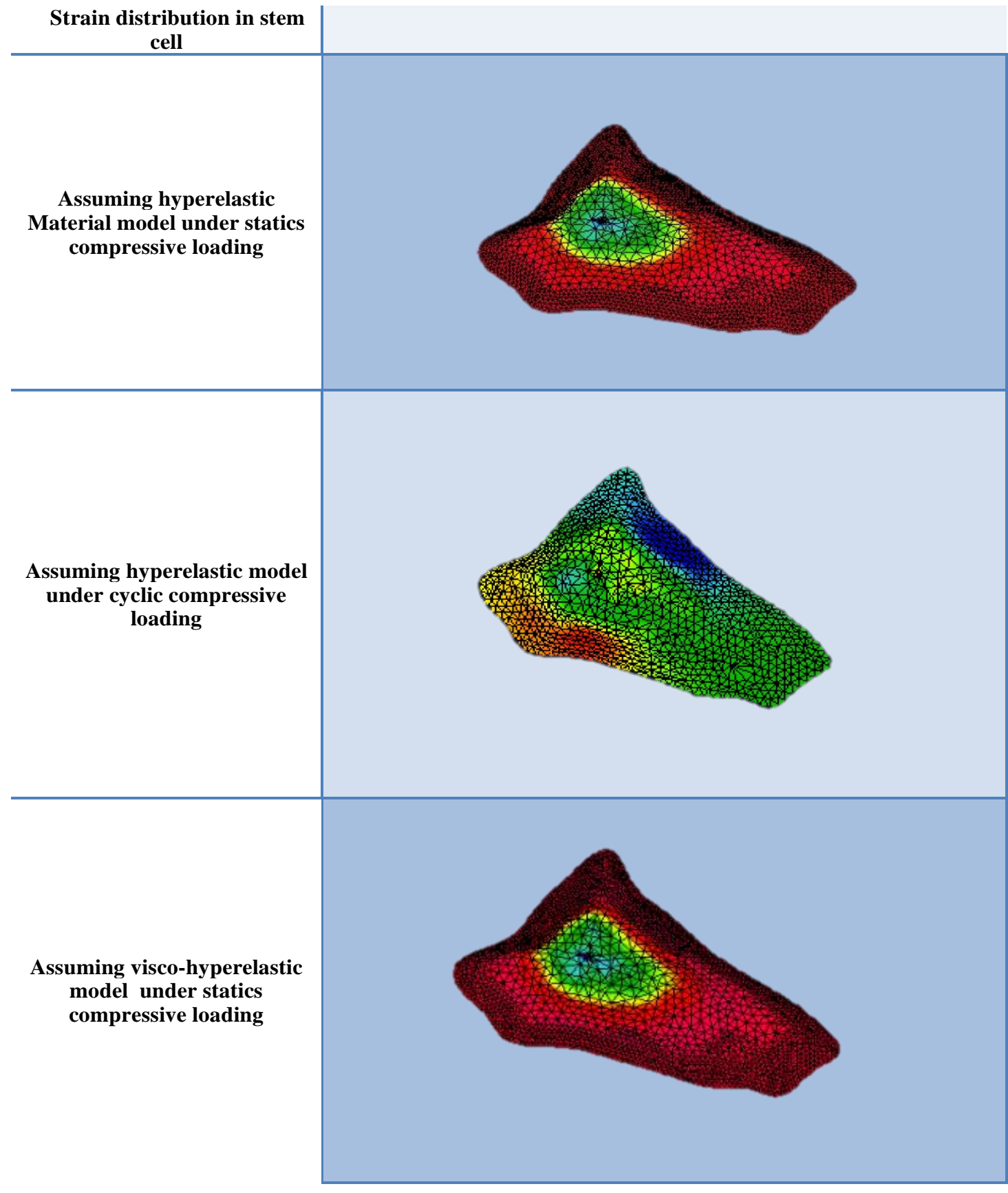

